\title{
Long non-coding RNA NEAT1 modifies cell proliferation, colony formation, apoptosis, migration and invasion via the miR-4500/BZW1 axis in ovarian cancer
}

\author{
HONGYING XU ${ }^{1 *}$, XIAOWEI SUN ${ }^{2 *}$, YING HUANG $^{1}, \mathrm{QIN} \mathrm{SI}^{3}$ and MAOKUN $\mathrm{LI}^{4}$ \\ Departments of ${ }^{1}$ Gynecology, ${ }^{2}$ Internal Medicine, ${ }^{3}$ Nursing and ${ }^{4}$ Surgery, Jingzhou Hospital of \\ Traditional Chinese Medicine, The Third Clinical Medical College of Yangtze University, Jingzhou, Hubei 434000, P.R. China
}

Received September 16, 2019; Accepted May 5, 2020

DOI: $10.3892 / \mathrm{mmr} .2020 .11408$

\begin{abstract}
Ovarian cancer (OC) is a frequently occurring malignant tumor in women. Increasing evidence has indicated that long non-coding RNA (lncRNA) nuclear paraspeckle assembly transcript 1 (NEAT1) participates in OC pathogenesis. Thus, the aim of the present study was to explore the function of NEAT1 during OC progression. The expression levels of NEAT1, microRNA (miR)-4500 and basic leucine zipper and W2 domain-containing protein 1 (BZW1) were assessed via reverse transcription-quantitative PCR and western blotting. Furthermore, cell proliferation, colony formation, apoptosis, migration and invasion were assessed using Cell-Counting Kit 8, colony formation, flow cytometry and Transwell assays, respectively. Cell glycolysis was analyzed using an XF96 metabolic flux analyzer, and the relationship between miR-4500 and NEAT1 or BZW1 was verified via dual-luciferase reporter and RNA binding protein immunoprecipitation assays. miR-4500 expression levels were low, whereas NEAT1 expression levels were high in OC tissues and cell lines compared with control tissues and cell lines. Moreover, the results indicated that NEAT1 was a sponge of miR-4500, which directly targeted BZW1. NEAT1 knockdown induced OC cell apoptosis, and inhibited OC cell proliferation, colony formation, migration, invasion and glycolysis. miR-4500 inhibitor reversed NEAT1 knockdown-mediated effects. Similarly, miR-4500 mimic-mediated effects on cell functions were reversed by BZW1 overexpression. In addition, the results indicated that
\end{abstract}

Correspondence to: Mr. Maokun Li, Department of Surgery, Jingzhou Hospital of Traditional Chinese Medicine, The Third Clinical Medical College of Yangtze University, 172 East Jiangjin Road, Jingzhou, Hubei 434000, P.R. China

E-mail: xuhongyingxhy@163.com

${ }^{*}$ Contributed equally

Key words: nuclear paraspeckle assembly transcript 1, microRNA-4500, basic leucine zipper and W2 domain-containing protein 1 , ovarian cancer
BZW1 expression was regulated by NEAT1 and miR-4500. Collectively, the present study suggested that NEAT1 modulated cell proliferation, colony formation, apoptosis, migration, invasion and glycolysis via the miR-4500/BZW1 axis in OC; therefore, NEAT1 may serve as a therapeutic target for OC.

\section{Introduction}

Ovarian cancer (OC) is a frequently occurring malignant tumor worldwide (1). At the stage of diagnosis, the majority of patients with OC present with cancer cell metastases (2). Despite significant advances in the treatment of OC, the therapeutic efficiency and prognosis of the disease remain unsatisfactory $(3,4)$. Therefore, although the pathogenesis of OC has been previously reported (5), the exact regulatory mechanism underlying OC requires further investigation.

Long non-coding RNAs (lncRNAs) are composed of $>200$ nucleotides and originate from the multitudinous class of genome transcripts (6). Increasing evidence has indicated that lncRNAs serve a vital role in diverse cellular functions, such as cell proliferation, apoptosis, migration and autophagy (7-9). Over the past few decades, it has been revealed that the aberrant expression of lncRNAs is associated with the progression and initiation of various tumors, including human OC (10-12). In particular, metastasis-associated lung adenocarcinoma transcript 1 is associated with poor prognosis and may serve as a biomarker in colorectal cancer (13). High expression levels of HOX transcript antisense RNA are related to poor prognosis and tumor metastasis in human OC (14). Moreover, lncRNA nuclear paraspeckle assembly transcript 1 (NEAT1), which is highly expressed in multiple types of cancer, is related to OC prognosis (15). In addition, it has also been reported that the aberrant expression of NEAT1 promotes tumorigenesis, metastasis and paclitaxel resistance in human OC $(16,17)$. The aforementioned studies indicate that NEAT1 is highly associated with OC progression, therefore, the precise function of NEAT1 in the molecular mechanisms underlying OC requires further investigation.

MicroRNAs (miRNAs/miRs) are a class of small non-coding RNAs ( 22 nucleotides in length) that can suppress target protein expression by repressing translation or promoting mRNA degradation (18). Previous studies have 
demonstrated that miRNA dysfunction participates in cancer progression (19-22). The role and sequences of miR-4500 have been previously reported $(23,24)$, and the inhibitory effects of miR-4500 on cancer progression have been partially identified $(25,26)$. For example, miR-4500 limits tumor development by targeting high mobility group AT-hook 2 in colorectal cancer (26). By contrast, the function of miR-4500 in OC is not completely understood; therefore, the present study aimed to explore the effects of miR-4500 on OC cell behaviors in vitro.

Basic leucine zipper and W2 domain-containing protein 1 (BZW1; also known as BZAP45) is expressed in a diverse number of human tissues and cell lines (27). BZW1 promotes salivary mucoepidermoid carcinoma development (28), whereas its influence during OC pathogenesis is not completely understood.

In the present study, the expression levels and roles of NEAT1, miR-4500 and BZW1 during the progression and initiation of $\mathrm{OC}$ were investigated.

\section{Materials and methods}

Patient samples and cell culture. The present study was approved by the Ethical Committee of Jingzhou Hospital of Traditional Chinese Medicine, The Third Clinical Medical College of Yangtze University. Written informed consent was obtained from all participants. Tumor tissues and adjacent noncancerous tissues ( $>5 \mathrm{~cm}$ from the tumor margin) were obtained from 30 patients with OC (aged 37-68 years) who received resection treatment at Jingzhou Hospital of Traditional Chinese Medicine, The Third Clinical Medical College of Yangtze University between June 2017 and June 2018. OC was validated by histological examination according to World Health Organization criteria (29). All patients had not received adjuvant chemotherapy prior to surgery.

The OC cell lines (CAOV3 and ES-2) were purchased from ATCC and normal control cells (IOSE80) were purchased from BeNa Culture Collection, Beijing Beina Chunglian Biotechnology Research Institute. CAOV3 and IOSE80 cells were cultured in DMEM (Corning Inc.), and ES-2 cells were cultured in McCoy's 5a (modified) Medium (Sigma-Aldrich; Merck KGaA). Both culture mediums were supplemented with 10\% FBS (Gibco; Thermo Fisher Scientific, Inc.), 100 units $/ \mathrm{ml}$ penicillin and $100 \mathrm{mg} / \mathrm{ml}$ streptomycin. Cells were cultured at $37^{\circ} \mathrm{C}$ with $5 \% \mathrm{CO}_{2}$.

Transient transfection. A small interfering RNA (siRNA) targeted against NEAT1 (si-NEAT1, 5'-GCCAUCAGCUUU GAAUAAAUU-3') and its negative control (NC; si-NC, 5'-UUCUCCGAACGUGUCACUTT-3') were designed by Guangzhou RiboBio Co., Ltd. BZW1 sequences were inserted into the pcDNA3.1 vector (Invitrogen; Thermo Fisher Scientific, Inc.) to construct a BZW1 overexpression vector. An empty pcDNA3.1 vector serves as the control (pcDNA). miR-4500 mimic (miR-4500, 5'-UGAGGUAGU AGUUUCUUGCGCC-3'), inhibitor (anti-miR-4500, 5'-GGC GCAAGA AACUACUACCUCA-3') and their relative controls (miR-NC, 5'-GAAAUGUACUUGAGCGUGGAG AC-3'; and anti-miR-NC, 5'-CUAAAACCGGCCGUACGG CGUU-3') were designed and synthesized by Guangzhou RiboBio Co., Ltd. BZW1 overexpression vector or pcDNA
$(0.2 \mu \mathrm{g})$ was transfected into CAOV3 and ES- 2 cells $\left(5 \times 10^{4}\right.$ cells $)$ with $0.5 \mu$ l Lipofectamine ${ }^{\circledR} 2000$ reagent (Invitrogen; Thermo Fisher Scientific, Inc.). Moreover, si-NEAT1, si-NC, miR-4500 mimic, anti-miR-4500, miR-NC or anti-miR-NC $(0.5 \mu \mathrm{g})$ was transfected into cells using $0.6 \mu \mathrm{l}$ Lipofectamine 2000 (Invitrogen; Thermo Fisher Scientific, Inc.), according to manufacturer's protocol. After $48 \mathrm{~h}$ transfection, the transfected cells were used for subsequent experiments.

Reverse transcription-quantitative PCR (RT-qPCR). Total RNA was extracted from patient samples and cell lines (CAOV3 and ES-2) using RNAiso Plus (Takara Biotechnology Co., Ltd.). Total RNA was reverse transcribed into cDNA using PrimeScript RT Master Mix (Takara Biotechnology Co., Ltd.) at $50^{\circ} \mathrm{C}$ for $15 \mathrm{~min}$ and $85^{\circ} \mathrm{C}$ for $5 \mathrm{sec}$. Subsequently, qPCR was performed using SYBR Premix Ex Taq II (Takara Biotechnology Co., Ltd) and an AB7900 Real-Time PCR System machine (Applied Biosystems; Thermo Fisher Scientific, Inc.). The amplification parameters were as follows: Denaturation at $95^{\circ} \mathrm{C}$ for $10 \mathrm{~min}$; followed by 40 cycles of denaturation at $95^{\circ} \mathrm{C}$ for $30 \mathrm{sec}$ and annealing at $60^{\circ} \mathrm{C}$ for $30 \mathrm{sec}$; and final extension at $72^{\circ} \mathrm{C}$ for $1 \mathrm{~min}$. The following primers (designed and synthesized by Guangzhou RiboBio Co., Ltd.) were used for qPCR: SOX4 forward, 5'-GGCCTG TTTCGCTGTCGGGT-3' and reverse, 5'-GCCTGCATGCAA CAGACTGGC-3'; HOTAIR forward, 5'-TAGGCAAATGTC AGAGGGTT-3' and reverse, 5'-CTTAAATTGGGCTGGGTC T-3'; plasmacytoma variant translocation 1 forward, 5'-TGA GAACTGTCCTTACGTGACC-3' and reverse, 5'-AGAGCA CCAAGACTGGCTCT-3'; growth arrest-specific transcript 5 forward, 5'-CCCAAGGAAGGATGAG-3' and reverse, 5'-ACCAGGAGCAGAACCA-3'; oryzacystatin-1 forward, 5'-TTCCAGCGCATGTCGGCGCTC-3' and reverse, 5'-GGT ACTAGTCCGTGGTTCTTC-3'; human ovarian cancer specific transcript 2 forward, 5'-GGACAGGTCCCTTGTTTC AA-3' and reverse, 5'-CTGGTCTTTCCTTGCCTCTG-3'; NEAT1 forward, 5'-TGGCTAGCTCAGGGCTTCAG-3' and reverse, 5'-TCTCCTTGCCAAGCTTCCTTC-3'; miR-4500 forward, 5'-CGTCGCACTGTGAGGTAGTAG-3' and reverse, 5'-TATGCTTGTTCTCGTCTCTGTGTC-3'; BZW1 forward, 5'-TACCGTCGATATGCAGAAACAC-3' and reverse, 5'-CCA TTAGCCAGAAGAACACCAG-3'; GAPDH forward, 5'-TGC ACCACCAACTGCTTAGC-3' and reverse, 5'-GGCATGCAC TGTGGTCATGAG-3'; and U6 forward, 5'-ATTGGAACG ATACAGAGAAGATT-3' and reverse, 5'-GGAACGCTTCAC GAATTTG-3'. miRNA and mRNA expression levels were quantified using the $2^{-\Delta \Delta \mathrm{Cq}}$ method (30) and normalized to the internal reference genes U6 and GAPDH, respectively.

Cell Counting Kit-8(CCK-8) assayfor cell proliferation.CAOV3 and ES- 2 cells were seeded $\left(5 \times 10^{4}\right.$ cells/well) into a 96-well plate. At $70 \%$ confluence, cells were transfected according to the aforementioned protocol. After incubation for 24,48 or $72 \mathrm{~h}$ at $37^{\circ} \mathrm{C}, \mathrm{CCK}-8$ reagent (Beyotime Institute of Biotechnology) was added to each well according to manufacturer's protocol. Following incubation for $4 \mathrm{~h}$ at $37^{\circ} \mathrm{C}$, the absorbance of each well was measured using a microplate reader.

Colony formation. Transfected CAOV3 and ES-2 cells $\left(5 \times 10^{2}\right.$ cells/well) were seeded into 6 -well plates and cultured 
for 2 weeks at $37^{\circ} \mathrm{C}$, and the culture medium was replaced with fresh medium every 4 days. Then, cells were washed using PBS, fixed with $4 \%$ paraformaldehyde for $15 \mathrm{~min}$ at room temperature, and stained with $0.5 \%$ crystal violet (Sigma-Aldrich; Merck $\mathrm{KGaA}$ ) for $10 \mathrm{~min}$ at room temperature. The number of colonies (containing >50 cells) was observed and counted using an optical microscope.

Flow cytometry assay to detect cell apoptosis. Cell apoptosis was detected using the Annexin V-FITC/PI detection kit (Nanjing KeyGen Biotech Co., Ltd.), according to the manufacturer's protocol. Briefly, transfected CAOV3 and ES-2 cells $\left(5 \times 10^{4}\right)$ were incubated with $5 \mu 1$ Annexin V-FITC and $5 \mu \mathrm{l}$ propidium iodide in the dark for $15 \mathrm{~min}$ at $4^{\circ} \mathrm{C}$. Apoptotic cells were detected by flow cytometry using a FACScan flow cytometer (BD Biosciences) and analyzed using Cell Quest software version 3.3 (BD Bioscience). The rate of apoptosis was presented as the percentage of early apoptosis OC cells in the total number of OC cells.

Transwell assay. At 60-80\% confluence, CAOV3 and ES-2 were transfected according to the aforementioned protocol. At $24 \mathrm{~h}$ post-transfection, cells were collected and washed with Hanks' balanced salt solution (Invitrogen; Thermo Fisher Scientific, Inc.). Cell migration and invasion were assessed using a 24-well Transwell system (pore size, $8 \mu \mathrm{m}$; Costar; Corning Inc.). To assess cell invasion, the upper chambers were precoated with Matrigel ${ }^{\circledR}$ at $4^{\circ} \mathrm{C}$ for $12 \mathrm{~h}$. Transfected cells $\left(5 \times 10^{4}\right.$ cells/well) were seeded into the upper chamber with $200 \mu \mathrm{l}$ serum-free medium. Complete medium with $10 \%$ FBS was seeded into the lower chamber. Following incubation for $24 \mathrm{~h}$ at $37^{\circ} \mathrm{C}$, migratory/invading cells were stained with $0.5 \%$ crystal violet (Sigma-Aldrich; Merck KGaA) at room temperature for $20 \mathrm{~min}$. Stained cells were observed and photographed using an inverted microscope.

Glycolysis analysis. The extracellular acidification rate (ECAR) of OC cells was evaluated using an XF96 metabolic flux analyzer (Seahorse Biosciences; Agilent Technologies, Inc.), according to the manufacturer's protocol. Briefly, $10 \mathrm{mM}$ glucose, $1 \mathrm{mM}$ oligomycin and $80 \mathrm{mM}$ 2-deoxyglucose were added at the indicated time points. Seahorse XF-96 Wave software (Seahorse Bioscience; Agilent Technologies, Inc.) was used to analyze the ECAR of OC cells.

Dual-luciferase reporter assay. StarBase (http://starbase. sysu.edu.cn/starbase2/) was used to screen the putative target. The complementary sequences between miR-4500 and wild-type (WT) or mutant (Mut) NEAT1 were amplified and cloned into the pGL3 basic vector (Promega Corporation) to construct luciferase reporter vectors (NEAT1-WT and NEAT1-Mut, respectively). Similarly, the complementary sequences between miR-4500 and WT or Mut BZW1 were cloned into the pGL3 basic vector to construct luciferase reporter vectors (BZW1-WT and BZW-Mut, respectively).

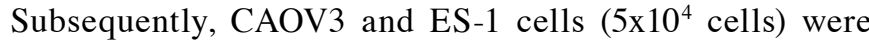
co-transfected with $400 \mathrm{ng}$ of luciferase reporter (NEAT1-WT, NEAT1-Mut, BZW-WT or BZW-Mut) and miR-4500 mimic (50 nM) using Lipofectamine 2000 (Invitrogen; Thermo Fisher Scientific, Inc.). After incubation for $48 \mathrm{~h}$ at $37^{\circ} \mathrm{C}$, luciferase activities were detected using the Dual-Luciferase Reporter Assay System (Promega Corporation), according to the manufacturer's protocol. Firefly luciferase activities were normalized to Renilla luciferase activities.

RNA binding protein immunoprecipitation (RIP). The RIP assay was performed using the Magna RIP RNA-Binding Protein Immunoprecipitation kit (EMD Millipore). Western blotting was performed to detect the expression levels of Ago2 (cat. no. ab32381; 1:1,000; Abcam) and RT-qPCR was performed to measure the expression levels of NEAT1 and miR-4500 in the precipitates. IgG served as the control (cat. no. ab150077; 1:1,000; Abcam).

Western blotting. Western blotting was performed as previously described (31). In brief, total protein was extracted from tissues and cell lines using RIPA lysis buffer (EMD Millipore). Total protein concentration was measured using a BCA Protein assay kit (Nanjing KeyGen Biotech Co., Ltd.), according to the manufacturer's protocol. Equal amounts of protein $(\sim 30 \mu \mathrm{g})$ were separated via SDS-PAGE on a $12 \%$ gel, and subsequently transferred onto PVDF membranes (EMD Millipore). After blocking with $5 \%$ skimmed milk at room temperature for $2 \mathrm{~h}$, the membranes were incubated overnight at $4^{\circ} \mathrm{C}$ with the following primary antibodies: BZW1 (cat. no. ab85090; 1:800; Abcam) and GAPDH (cat. no. ab8245; 1:8,000; Abcam). Following primary incubation, the membranes were incubated with horseradish peroxidase (HRP)-conjugated goat anti-rabbit IgG H\&L (cat. no. ab205718; 1:2,000; Abcam) and HRP-conjugated goat anti-mouse IgG H\&L (cat. no. ab205719; 1:2,000; Abcam) at room temperature for $40 \mathrm{~min}$. Protein bands were visualized using the Enhanced Chemiluminescence Plus kit (EMD Millipore) and semi-quantified by densitometric analysis of protein signals using ImageJ version 1.49 (National Institutes of Health).

Statistical analysis. All experiments were repeated at least three times. Statistical analyses were performed using GraphPad software (version 5.0; GraphPad Software, Inc.). Data are expressed as the mean \pm SD. Differences between paired tumor tissues and adjacent noncancerous tissues were analyzed using the paired Student's t-test. Differences between two groups were analyzed using the unpaired Student's t-test. Differences among multiple groups were analyzed using one-way ANOVA followed by Tukey's post hoc test. Spearman's correlation coefficient was used to analyze the relationship between miR-4500 expression and NEAT1 expression. $\mathrm{P}<0.05$ was considered to indicate a statistically significant difference.

\section{Results}

NEAT1 is upregulated in OC tissues and cell lines. RT-qPCR was performed to assess the expression of multiple lncRNAs in 30 paired $\mathrm{OC}$ and adjacent noncancerous tissue samples. NEAT1 was chosen for subsequent experiments as it displayed the highest expression levels in tumor samples compared with matched normal tissue samples (Fig. 1A). The expression levels of NEAT1 in OC cell lines (CAOV3 and ES-2) were also detected via RT-qPCR. The results indicated that NEAT1 expression was significantly higher in OC cell lines compared 


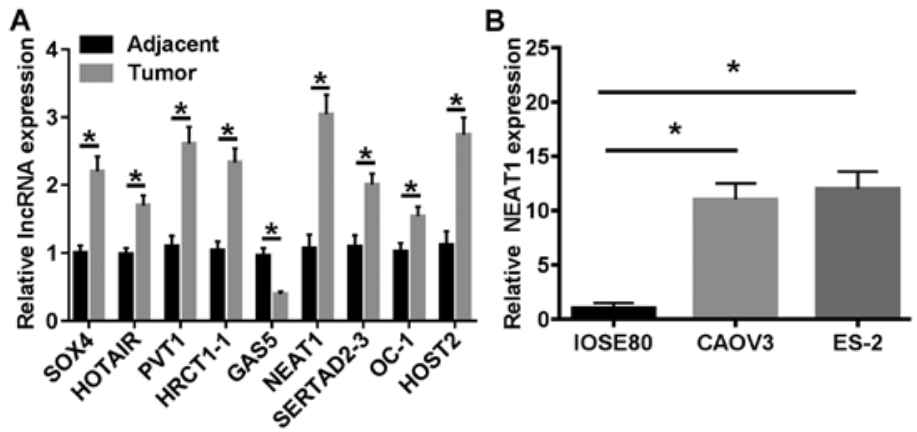

Figure 1. NEAT1 is upregulated in OC tissues and cell lines. (A) lncRNA expression levels in OC tissues and adjacent noncancerous tissues. (B) NEAT1 expression levels in OC cell lines and a control cell line. ${ }^{*} \mathrm{P}<0.05$, as indicated. NEAT1, nuclear paraspeckle assembly transcript 1; OC, ovarian cancer; lncRNA, long non-coding RNA.

A

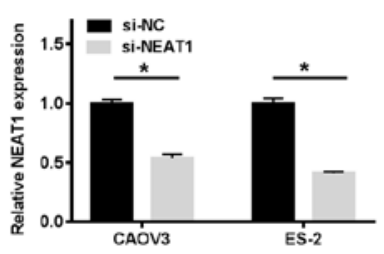

B

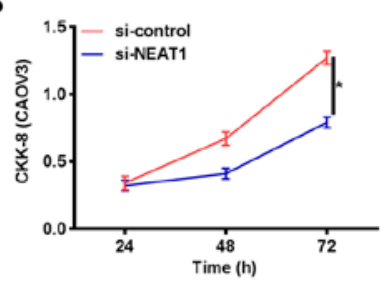

C

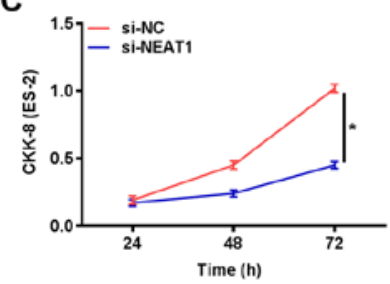

D

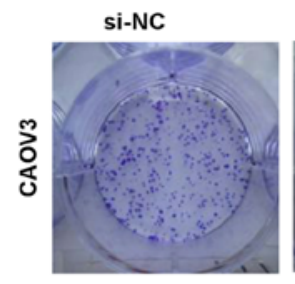

si-NEAT1
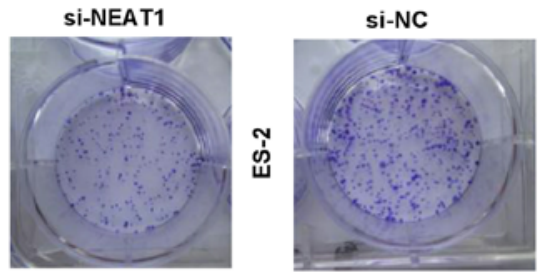

si-NEAT1
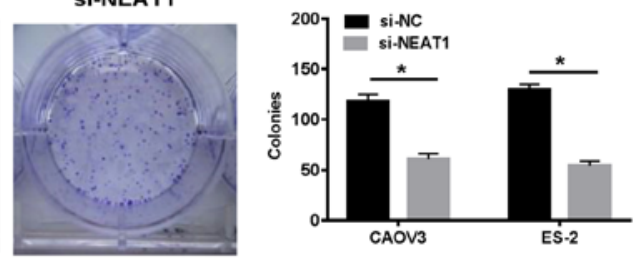

E
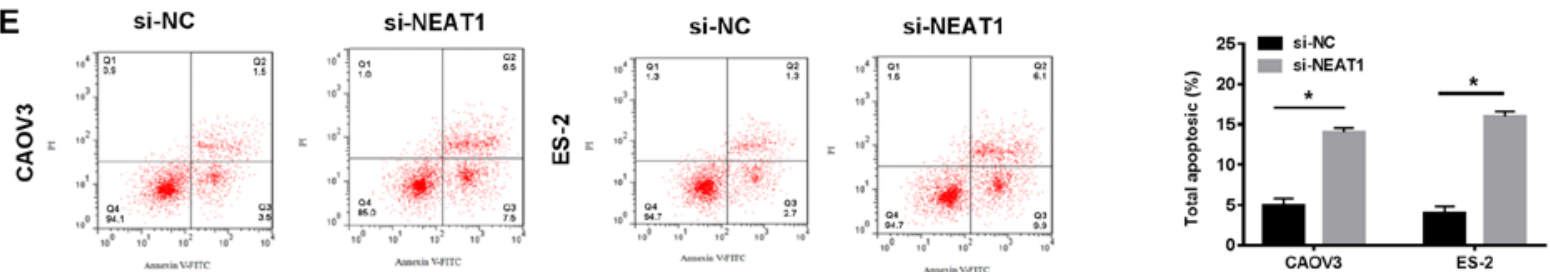

F
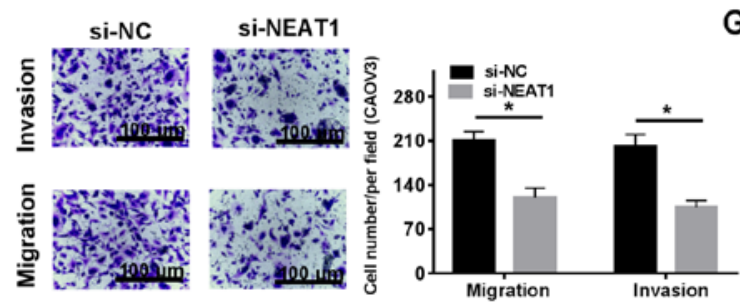

G
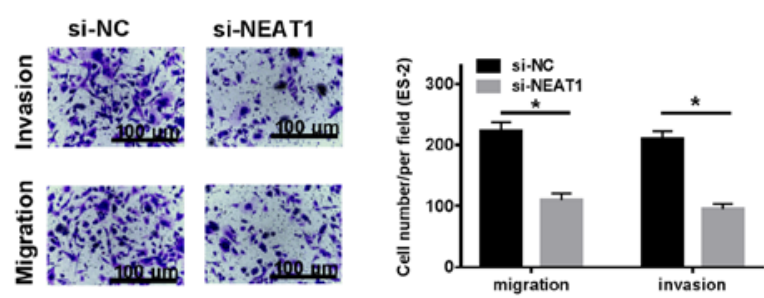

H

CAOV3
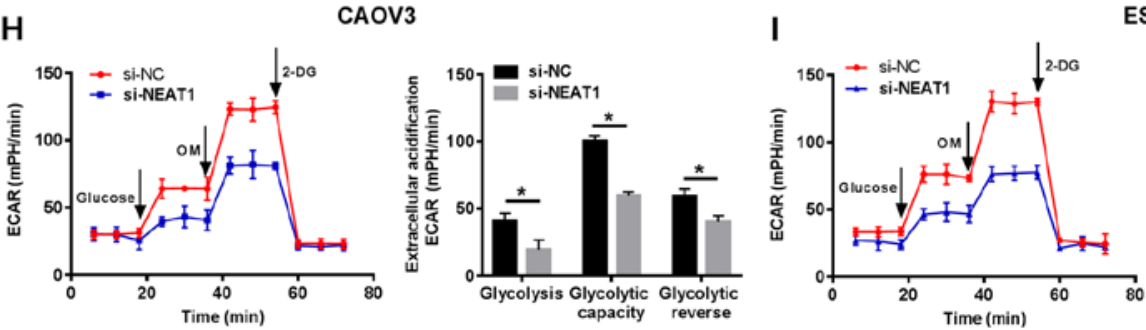

ES-2

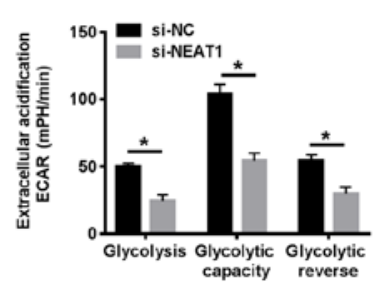

Figure 2. NEAT1 knockdown increases cell apoptosis, and inhibits cell proliferation, colony formation, migration, invasion and glycolysis in vitro. CAOV3 and ES-2 cells were transfected with si-NEAT1 or si-NC. (A) Transfection efficiency of NEAT1 knockdown. The CCK-8 assay was performed to assess (B) CAOV3 and (C) ES-2 cell proliferation at $72 \mathrm{~h}$. (D) The colony formation assay was performed to assess colony formation. (E) Cell apoptosis was assessed via flow cytometry. (F) CAOV3 and (G) ES-2 cell migration and invasion were determined using Transwell assays (magnification, $\mathrm{x} 100$ ). ECAR in (H) CAOV3 and (I) ES-2 cells was detected using an XF96 metabolic flux analyzer. "P<0.05, as indicated. NEAT1, nuclear paraspeckle assembly transcript 1; si, small interfering RNA; NC, negative control; CCK-8, Cell Counting Kit-8; ECAR, extracellular acidification rate; PI, propidium iodide; OM, oligomycin; 2-DG, 2-deoxyglucose. 
A

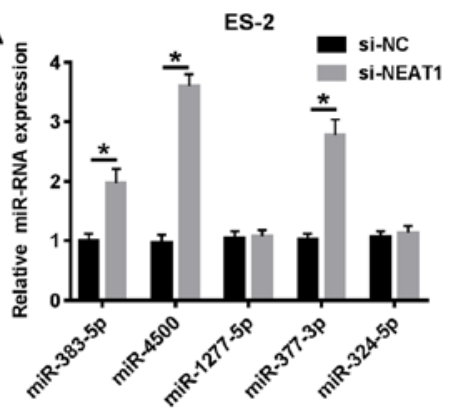

B

NEAT1-WT 5'-cttggtCTGTCTACCTCg-3'

miR-4500 3'- ttctttGAT-GATGGAGt-5'

NEAT1-MUT 5'-cttggtGAGTGATGGAGg-3'
C

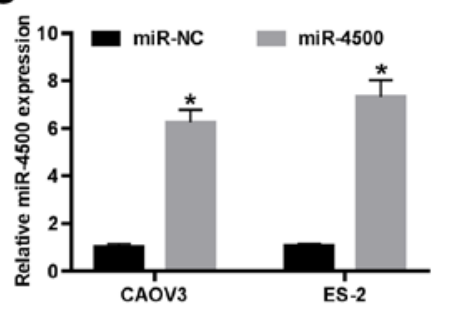

$\mathbf{F}$

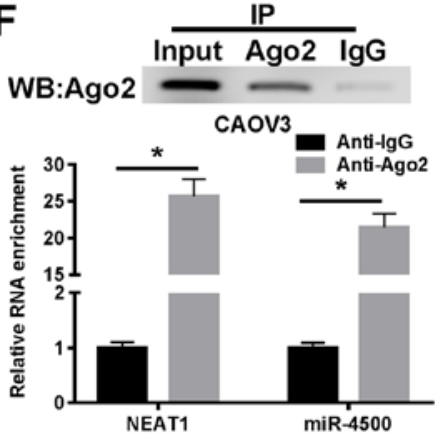

I

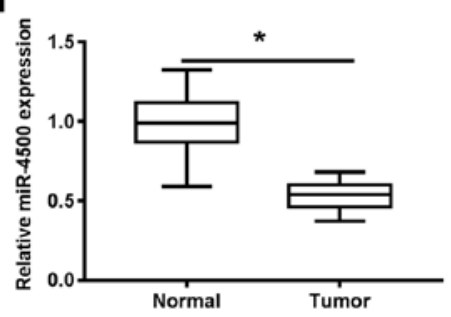

D

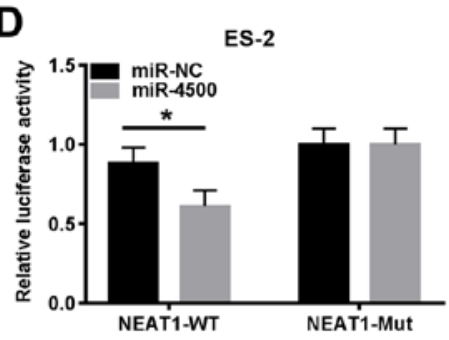

G

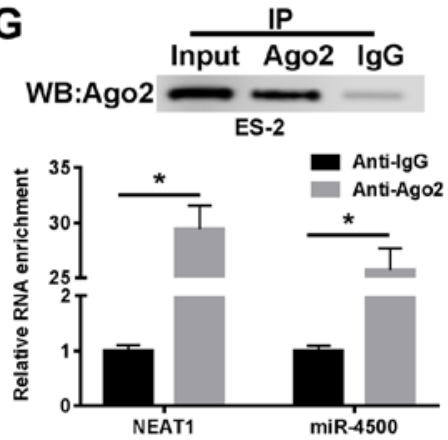

$J$

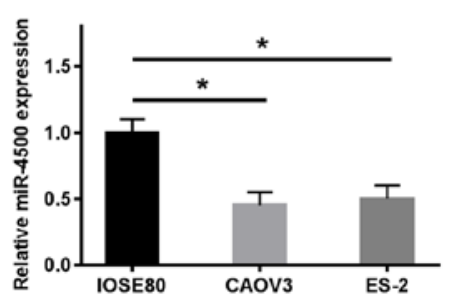

E

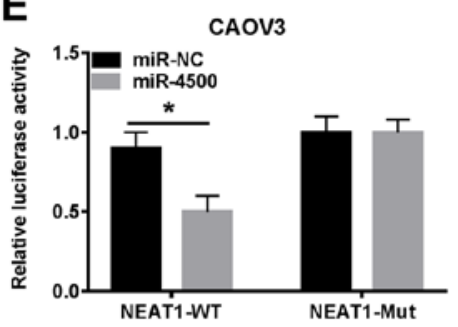

H

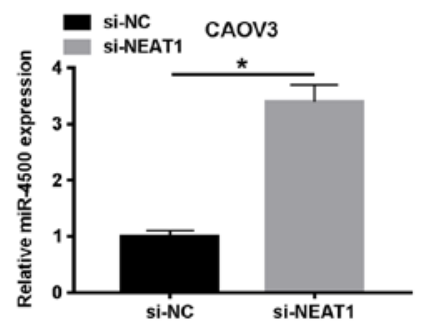

$\mathbf{K}$

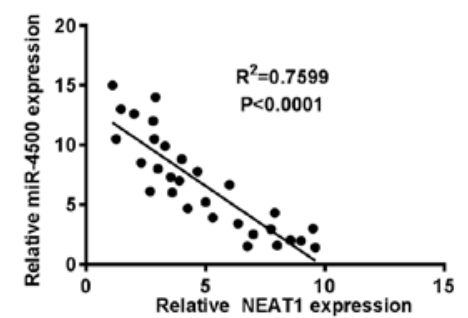

Figure 3. NEAT1 is a sponge of miR-4500. (A) miRNA expression levels in si-NC and si-NEAT1-transfected cells. (B) The binding sites (red) between miR-4500 and NEAT1 were predicted using starBase. (C) Transfection efficiency of miR-4500 mimic. Dual-luciferase reporter assays were performed to investigate the relationship between miR-4500 and NEAT1 in (D) ES-2 and (E) CAOV3 cells. The RNA binding protein immunoprecipitation assay was conducted to validate the relationship between miR-4500 and NEAT1 in (F) CAOV3 and (G) ES-2 cells. (H) miR-4500 expression levels in CAOV3 cells following transfection with si-NEAT1 or si-NC. miR-4500 expression levels in ovarian cancer (I) tissues and (J) cell lines. (K) The correlation between miR-4500 expression and NEAT1 expression. ${ }^{*} \mathrm{P}<0.05$, as indicated. NEAT1, nuclear paraspeckle assembly transcript 1 ; miR, microRNA; si, small interfering RNA; NC, negative control; WT, wild-type; Mut, mutant; IP, immunoprecipitation; WB, western blotting.

with normal ovarian cells (Fig. 1B). Collectively, the results demonstrated that the aberrant expression of NEAT1 may be associated with the progression of human OC.

NEAT1 knockdown increases cell apoptosis, and decreases cell proliferation, colony formation, migration, invasion and glycolysis in vitro. To investigate whether NEAT1 served a critical role in ovarian carcinogenesis, NEAT1 knockdown was performed in CAOV3 and ES-2 cells. si-NEAT1 significantly reduced NEAT1 expression levels compared with si-NC (Fig. 2A). CAOV3 and ES-2 cell proliferation was assessed by the CCK-8 assay, which indicated that NEAT1 knockdown significantly decreased cell proliferation in both cell lines compared with si-NC (Fig. 2B and C). In addition, the effect of si-NEAT1 on colony formation was assessed. Colony formation was inhibited by NEAT1 knockdown in OC cell lines (Fig. 2D). By contrast, cell apoptosis was significantly increased following transfection with si-NEAT1 compared with si-NC (Fig. 2E). Furthermore, the role of NEAT1 in cell migration and invasion was analyzed using Transwell assays. The results suggested that CAOV3 and ES-2 cell migration and invasion were significantly inhibited by si-NEAT1 compared with si-NC (Fig. 2F and G). Moreover, si-NEAT1 significantly inhibited OC cell glycolysis compared with si-NC 

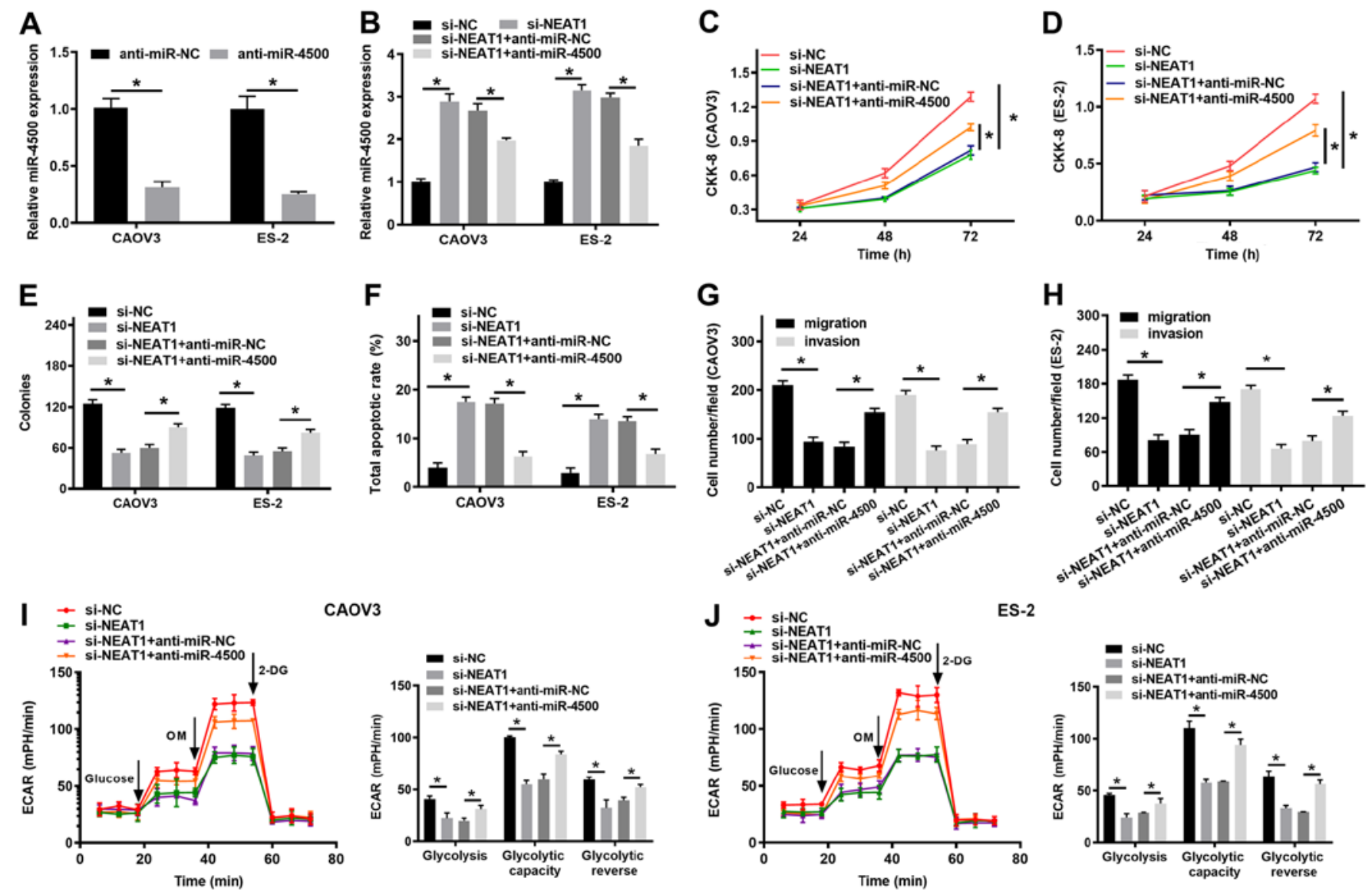

Figure 4. miR-4500 inhibitor reverses NEAT1 knockdown-mediated effects on cell behavior. (A) Transfection efficiency of anti-miR-4500. (B) miR-4500 expression levels in CAOV3 and ES-2 cells transfected with si-NC, si-NEAT1, si-NEAT1 + anti-miR-NC or si-NEAT1 + anti-miR-4500. The CCK-8 assay was performed to assess (C) CAOV3 and (D) ES-2 cell proliferation at $72 \mathrm{~h}$. (E) The effects of NEAT1 knockdown and miR-4500 inhibitor on colony formation. (F) Cell apoptosis was assessed via flow cytometry. Transwell assays were conducted to investigate the effect of NEAT1 knockdown and miR-4500 inhibitor on (G) CAOV3 and (H) ES-2 cell migration and invasion. ECAR in (I) CAOV3 and (J) ES-2 cells determined using an XF96 metabolic flux analyzer. "P<0.05, as indicated. miR, microRNA; NEAT1, nuclear paraspeckle assembly transcript 1; si, small interfering RNA; NC, negative control; CCK-8, Cell Counting Kit-8; ECAR, extracellular acidification rate; OM, oligomycin; 2-DG, 2-deoxyglucose.

(Fig. 2H and I). The aforementioned results indicated that NEAT1 knockdown suppressed OC cell progression in vitro.

NEAT1 is a sponge of miR-4500. The starBase database was used to predict potential targets of NEAT1, and RT-qPCR was performed to detect the expression levels of the potential targets in si-NC and si-NEAT1-transfected ES-2 cells. Following NEAT1 knockdown, the expression levels of miR-4500 were significantly increased in ES-2 cells compared with si-NC-transfected ES-2 cells (Fig. 3A). Furthermore, the binding sites between miR-4500 and NEAT1 were identified (Fig. 3B). The transfection efficiency of miR- $4500 \mathrm{mimic}$ is presented in Fig. 3C. Subsequently, CAOV3 and ES-2 cells were transfected with luciferase reporters, including NEAT1-WT and NEAT1-Mut. miR-4500 mimic significantly inhibited NEAT-WT luciferase activities in CAOV 3 and ES-2 cells compared with miR-NC. By contrast, miR-4500 mimic displayed no effect on the luciferase activities of NEAT1-Mut (Fig. 3D and E). The binding between miR-4500 and NEAT1 was also verified using the RIP assay (Fig. $3 F$ and G). In addition, NEAT1 knockdown significantly upregulated miR-4500 expression in CAOV3 cells compared with si-NC-transfected cells (Fig. 3H). miR-4500 expression levels were significantly decreased in OC tissue samples and cell lines compared with the corresponding controls (Fig. 3I and J). The results also indicated that miR-4500 expression was negatively correlated with NEAT1 expression (Fig. 3K). Therefore, the results indicated that miR-4500 was targeted by NEAT1.

miR-4500 inhibitor abolishes NEAT1 knockdown-mediated effects on cell behaviors. Based on the interaction between NEAT1 and miR-4500, CAOV3 and ES-2 cells were transfected with si-NC, si-NEAT1, si-NEAT1 + anti-miR-NC or si-NEAT1 + anti-miR-4500. miR-4500 knockdown significantly decreased miR-4500 expression levels compared with the anti-miR-NC group (Fig. 4A). miR-4500 knockdown also reversed NEAT1 knockdown-mediated effects on miR-4500 expression (Fig. 4B). Furthermore, NEAT1 knockdown-mediated inhibition of cell proliferation was decreased by miR-4500 knockdown (Fig. 4C and D). Similarly, the inhibitory effects of NEAT1 knockdown on colony formation were reversed by miR-4500 knockdown (Figs. 4E and S1A). miR-4500 knockdown also decreased the rate of NEAT1 knockdown-induced cell apoptosis (Figs. 4F and S1B). Cell migration and invasion were assessed using the Transwell assay, which indicated that si-NEAT1 significantly decreased cell migration and invasion 
BZW1 3'UTR 5' ...GGUUCUUACAUCUUCCUACCUCC... WT

hsa-miR-4500 3' UUCUUUGAUGAUGGAGU 5'

BZW1 3'UTR 5' ...GGUUCUUACAUCUUCGAUGGAGC...3' Mut

B

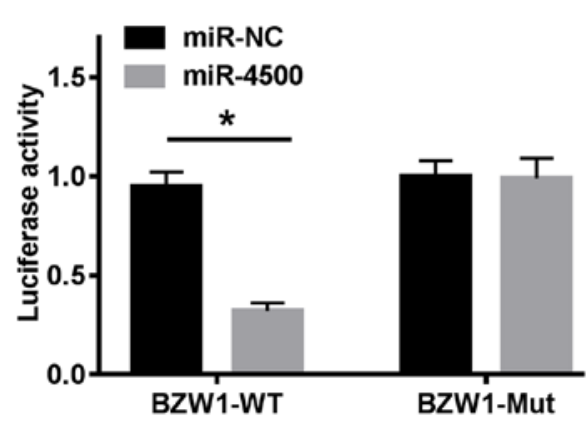

D

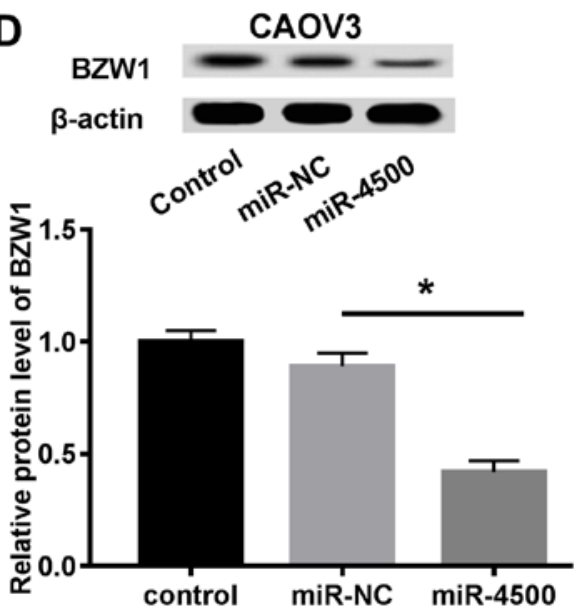

C

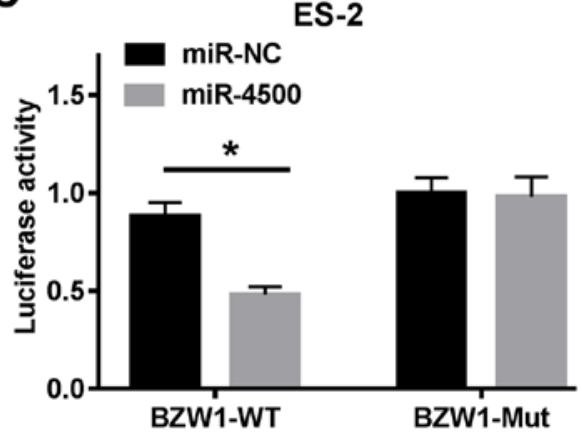

E

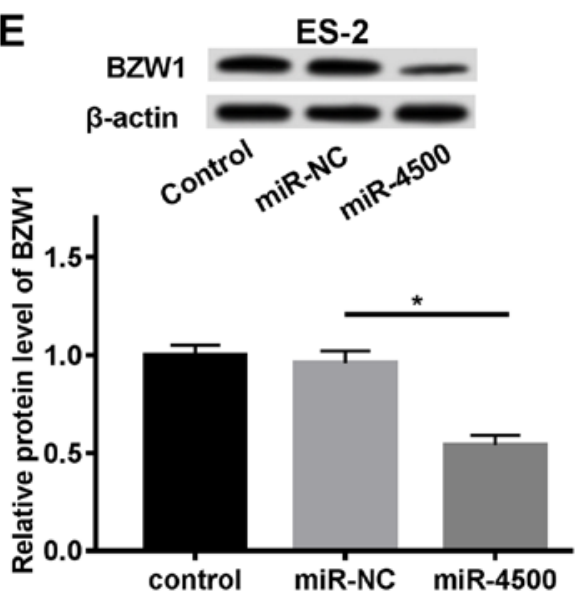

Figure 5. BZW1 is a target gene of miR-4500. (A) The binding sites between miR-4500 and BZW1 (red) were predicted using starBase. Dual-luciferase reporter assays were performed to investigate the interaction between miR-4500 and BZW1 in (B) CAOV3 and (C) ES-2 cells. The effect of miR-4500 mimic on BZW1 expression in (D) CAOV3 and (E) ES-2 cells. * $\mathrm{P}<0.05$, as indicated. BZW1, basic leucine zipper and W2 domain-containing protein 1; miR, microRNA; UTR, untranslated region; NC, negative control; WT, wild-type; Mut, mutant.

compared with si-NC. However, following transfection with miR-4500 inhibitor, NEAT1 knockdown-mediated effects on cell migration and invasion were reversed (Figs. 4G, H, S1C and D). Moreover, miR-4500 knockdown reversed the inhibitory effect of NEAT1 knockdown on OC cell glycolysis (Fig. 4I and J). Taken together, the results indicated that NEAT1 knockdown-mediated effects on cell proliferation, colony formation, apoptosis, migration, invasion and glycolysis were reversed by miR-4500 knockdown.

BZW1 is a target gene of $m i R-4500$. Subsequently, the mechanism underlying the tumor suppressor role of miR-4500 in OC carcinogenesis was investigated. The potential target genes of miR-4500 were predicted and a common fragment domain between miR-4500 and BZW1 was identified (Fig. 5A). The dual-luciferase reporter assay suggested that the luciferase activities of the WT group were significantly reduced by miR-4500 mimic compared with miR-NC, whereas miR-4500 mimic did not alter the luciferase activities of the Mut group (Fig. 5B and C). The protein expression levels of BZW1 were evaluated via western blotting. miR-4500 mimic decreased BZW protein expression levels in both CAOV3 and ES-2 cells compared with miR-NC (Fig. 5D and E), which indicated that BZW1 was directly targeted by miR-4500.

BZW1 overexpression reverses $m i R-4500$-mediated effects on $O C$ cell behavior. Based on the molecular mechanism between miR-4500 and BZW1, subsequent assays were performed to identify the regulatory function between miR-4500 and BZW1. The transfection efficiency of the BZW1 overexpression vector is presented in Fig. 6A. Subsequently, CAOV3 and ES-2 cells were transfected with miR-NC + pcDNA, miR-4500 + pcDNA or miR-4500 + BZW1 overexpression vector. The protein expression levels of BZW1, which were significantly inhibited by miR-4500 mimic, were restored by BZW1 overexpression (Fig. 6B and C). Moreover, BZW1 overexpression inhibited the repressive effect of miR-4500 mimic on CAOV3 and ES-2 cell proliferation (Fig. 6D and E). Similarly, colony formation, which was significantly inhibited by miR-4500 mimic, was rescued following BZW1 overexpression (Figs. 6F and S2A). In addition, the rate of miR-4500 mimic-induced cell apoptosis was decreased by BZW1 overexpression (Figs. 6G and S2B). The Transwell assay indicated that BZW1 overexpression partially reversed 
A

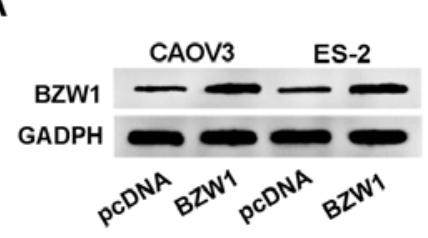

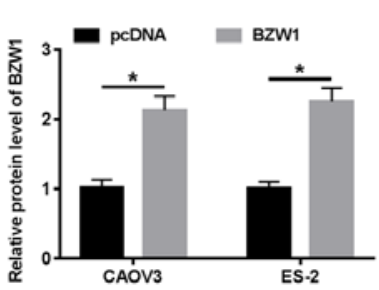

B

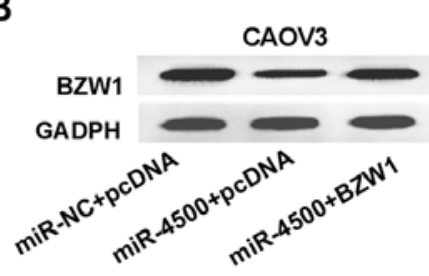

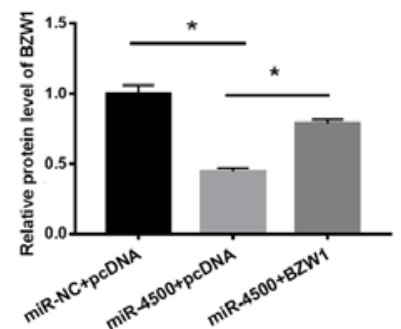

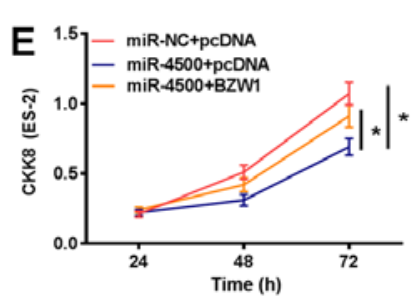

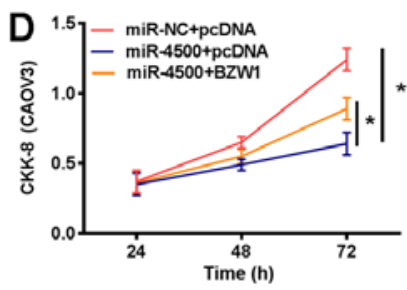

C

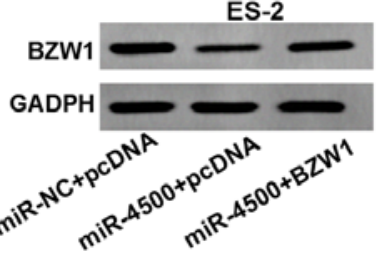

$\mathbf{F}$

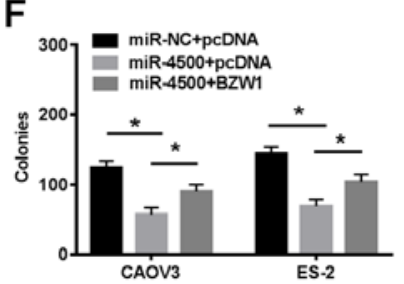

G
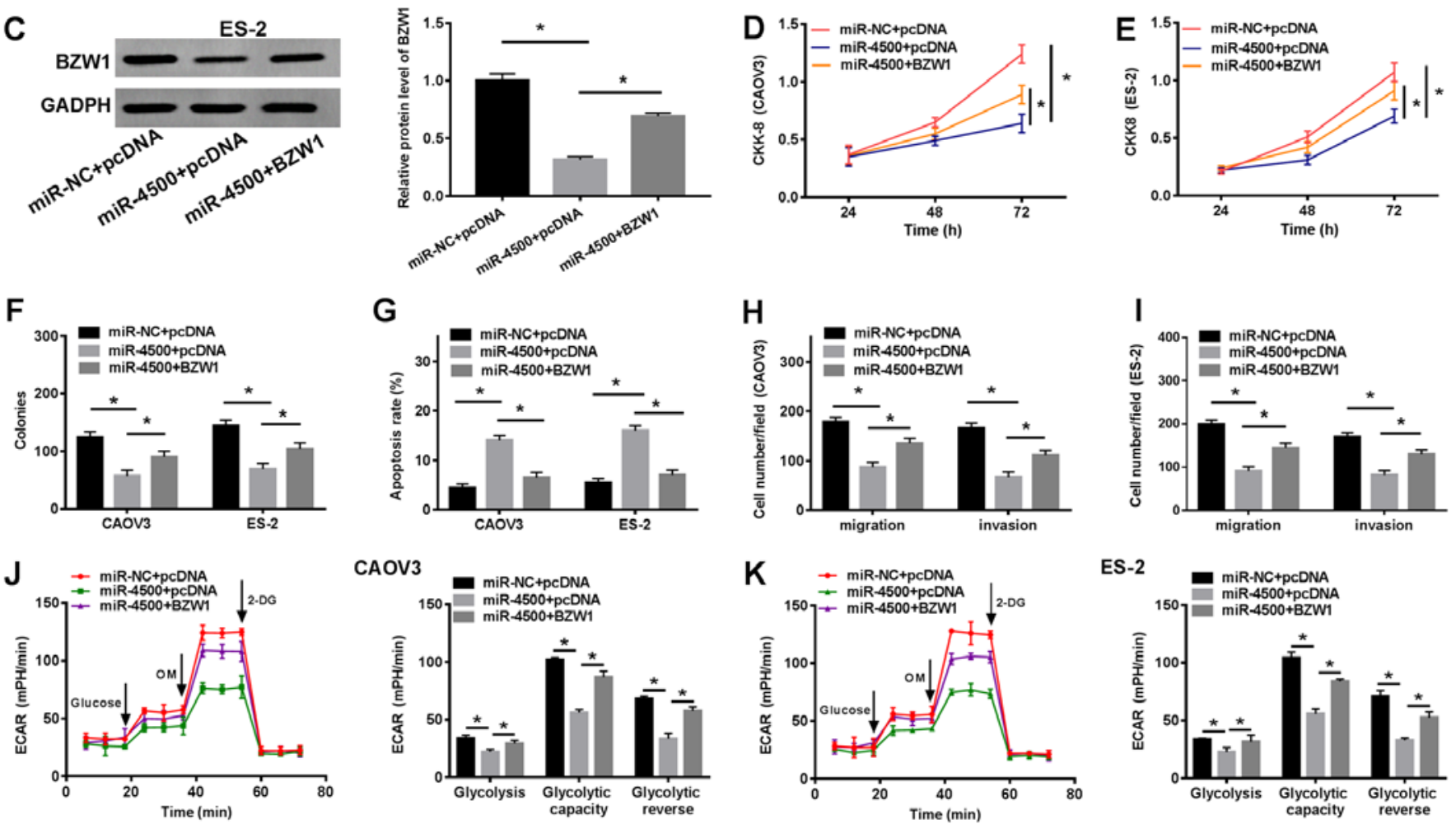

Figure 6. BZW1 overexpression reverses miR-4500 mimic-mediated effects on OC cell behavior. (A) Transfection efficiency of BZW1 overexpression. CAOV3 and ES-2 cells were transfected with miR-NC + pcDNA, miR-4500 + pcDNA or miR-4500 + BZW1. BZW1 protein expression levels in (B) CAOV3 and (C) ES-2 cells. The CCK-8 assay was performed to assess (D) CAOV3 and (E) ES-2 cell proliferation at 72 h. (F) Colony formation was evaluated by performing a colony formation assay. (G) OC cell apoptosis was determined via flow cytometry. Transwell assays were performed to investigate the function of miR-4500 and BZW1 in (H) CAOV3 and (I) ES-2 cell migration and invasion. ECAR in (J) CAOV3 and (K) ES-2 cells was determined using an XF96 metabolic flux analyzer. "P $<0.05$, as indicated. BZW1, basic leucine zipper and W2 domain-containing protein 1; miR, microRNA; OC, ovarian cancer; NC, negative control; CCK-8, Cell Counting Kit-8; ECAR, extracellular acidification rate; OM, oligomycin; 2-DG, 2-deoxyglucose.

the inhibitory effects of miR-4500 mimic on OC cell migration and invasion (Figs. 6H, I, S2C and D). Furthermore, miR-4500 mimic-mediated inhibition of glycolysis was recovered by BZW1 overexpression (Fig. 6J and K). Collectively, the results indicated that miR-4500 mimic-mediated effects on cell behavior were reversed by BZW1 overexpression.

BZW1 expression is co-regulated by NEAT1 and miR-4500. Based on the biological roles of NEAT1, miR-4500 and BZW1 in OC pathogenesis, the underlying modulatory mechanism was investigated. The present study aimed to investigate how BZW1 expression was regulated in OC. Following transfection with si-NC, si-NEAT1, si-NEAT1 + anti-miR-NC or si-NEAT1 + anti-miR-4500, the mRNA expression levels of BZW1 in CAOV3 and ES-2 cells were determined via RT-qPCR. The results indicated that NEAT1 knockdown significantly decreased the mRNA expression levels of BZW1 compared with si-NC, which was reversed by miR- 4500 inhibitor (Fig. 7A and B). Furthermore, the protein expression levels of BZW1 were measured by performing western blotting and displayed a similar pattern to mRNA expression levels (Fig. 7C and D). In summary, the results indicated that the mRNA and protein expression levels of BZW1 were modulated by NEAT1 and miR-4500 in $\mathrm{OC}$ cell lines.

\section{Discussion}

lncRNAs participate in the progression of various tumors, with a number of lncRNAs serving as sponges of miRNAs (32). For example, it has been reported that growth arrest-specific 5 is closely associated with multiple types of cancer, such as breast and gastric cancer (33-35). NEAT1, the target lncRNA investigated in the present study, responds to proteasome inhibition (36) and is associated with the poor survival of patients with breast cancer (37). In the present 
A

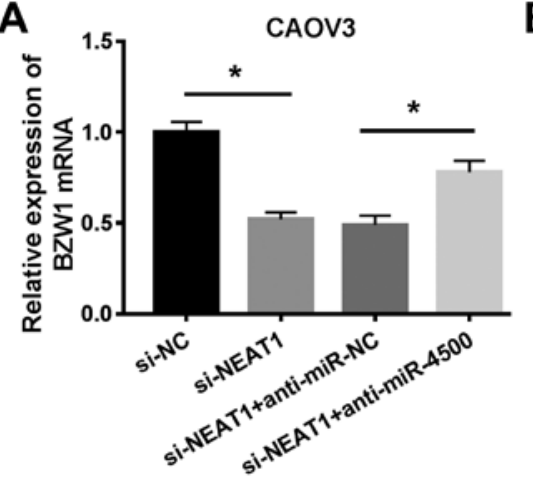

C

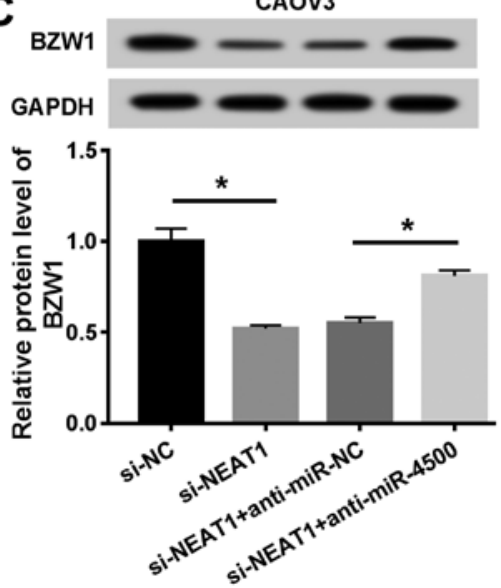

B

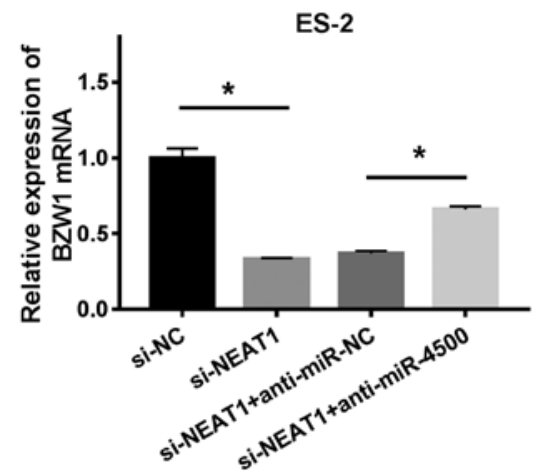

D

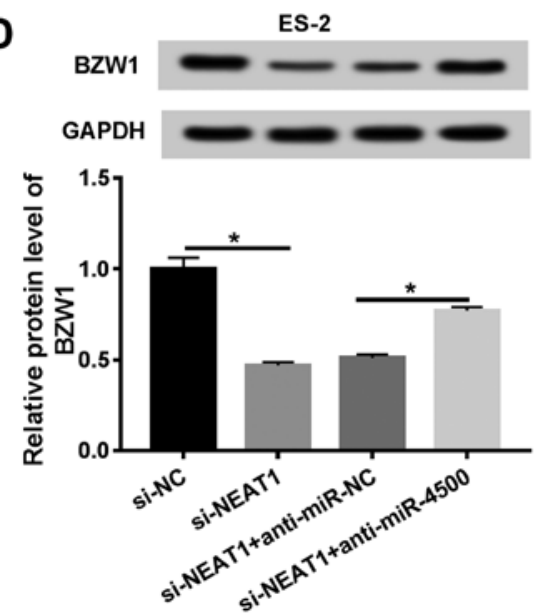

Figure 7. BZW1 expression is co-regulated by NEAT1 and miR-4500. CAOV3 and ES-2 cells were transfected with si-NC, si-NEAT1, si-NEAT1 + anti-miR-NC or si-NEAT1 + anti-miR-4500. BZW1 mRNA expression levels in (A) CAOV3 and (B) ES-2 cells. BZW1 protein expression levels in (C) CAOV3 and (D) ES-2 cells. ${ }^{*} \mathrm{P}<0.05$, as indicated. BZW1, basic leucine zipper and W2 domain-containing protein 1; NEAT1, nuclear paraspeckle assembly transcript 1 ; miR, microRNA; si, small interfering RNA; NC, negative control.

study, NEAT1 expression levels were significantly increased in OC tissues and cell lines (CAOV3 and ES-2) compared with control tissues and cell lines, which was consistent with a previous study (15). Furthermore, it has been reported that NEAT1 mediates oncogenic growth by altering the epigenetic landscape of target genes, thereby promoting oncogenic gene transcription in prostate cancer (38). However, the functions of NEAT1 during human OC development require further investigation. Based on the high expression of NEAT1 in OC, the specific role of NEAT1 knockdown on OC cell behaviors, such as cell proliferation, colony formation, apoptosis, migration, invasion and glycolysis, was investigated in the present study. NEAT1 knockdown enhanced cell apoptosis, but inhibited cell proliferation, colony formation, migration, invasion and glycolysis in vitro. The results indicated that NEAT1 may serve as an oncogene in OC pathogenesis and NEAT1 knockdown may suppress the progression of OC. Although it has been reported that NEAT1 is a sponge of miR-34a-5p in OC (39), further molecular functions of NEAT1 require investigation.

Several studies have demonstrated that lncRNAs regulate target miRNAs $(40,41)$. NEAT1 may monitor tumorigenesis and malignant progression by sponging miRNAs (42). miR-4500 has been identified as a tumor suppressor in a number of diseases, including non-small cell lung (25) and colorectal (26) cancer. In the present study, the interaction between miR-4500 and NEAT1 was predicted and verified.
The results suggested that NEAT1 regulated cell functions by targeting miR-4500. In addition, miR-4500 inhibitor reversed NEAT1 knockdown-mediated effects on OC cell behaviors, including cell proliferation, colony formation, apoptosis, migration, invasion and glycolysis. Based on the function of miR-4500 during OC progression, the target genes of miR-4500 need to be identified.

A previous study demonstrated that BZW1, which belongs to the bZIP superfamily of transcription factors, serves a crucial role in salivary mucoepidermoid carcinoma (28). In the present study, BZW1 was identified as a target gene of miR-4500. The effects of miR-4500 mimic on OC cell functions were reversed by BZW1 overexpression. The aforementioned results indicated that BZW1 may serve a promoting role during OC progression, which was consistent with a previous study (43).

Collectively, the present study indicated that NEAT1 may serve as an oncogene during OC progression. NEAT1 knockdown facilitated cell apoptosis, and inhibited cell proliferation, colony formation, migration, invasion and glycolysis. The effects of NEAT1 knockdown were reversed by miR-4500 knockdown and the tumor suppressive effects of miR-4500 were reversed by BZW1 overexpression. miR-4500 was identified as target of NEAT1 and directly targeted BZW1. The results indicated that NEAT1 mediated cell behavior and tumor progression via the miR-4500/BZW1 axis in human OC. However, the present study did not identify the regulatory 
mechanism underlying NEAT1 in OC progression and initiation; therefore, the biological role of NEAT1 in human diseases requires further investigation.

\section{Acknowledgements}

Not applicable.

\section{Funding}

No funding was received.

\section{Availability of data and materials}

The datasets used and/or analyzed during the current study are available from the corresponding author on reasonable request.

\section{Authors' contributions}

HX conceived and designed the study. XS and YH performed the experiments. QS and ML analyzed the data and wrote the manuscript. All authors read and approved the final manuscript.

\section{Ethics approval and consent to participate}

The present study was approved by the Ethical Committee of Jingzhou Hospital of Traditional Chinese Medicine, The Third Clinical Medical College of Yangtze University. Written informed consent was obtained from all participants.

\section{Patient consent for publication}

Not applicable.

\section{Competing interests}

The authors declare that they have no competing interests.

\section{References}

1. Siegel RL, Miller KD and Jemal A: Cancer statistics, 2018. CA Cancer J Clin 68: 7-30, 2018.

2. Eisenhauer EA: Real-world evidence in the treatment of ovarian cancer. Ann Oncol 28 (Suppl 8): VIII61-VVIII5, 2017.

3. Rustin GJ, Van Der Burg MEL, Griffin CL, Guthrie D, Lamont A, Jayson GC, Kristensen G, Mediola C, Coens C, Qian W, et al Early versus delayed treatment of relapsed ovarian cancer (MRC OV05/EORTC 55955): A randomised trial. Lancet 376: $1155-1163,2010$.

4. Jayson GC, Kohn EC, Kitchener HC and Ledermann JA: Ovarian cancer. Lancet 384: 1376-1388, 2014.

5. Kroeger Jr PT and Drapkin R: Pathogenesis and heterogeneity of ovarian cancer. Curr Opin Obstet Gynecol 29: 26-34, 2017.

6. Mattick JS and Rinn JL: Discovery and annotation of long noncoding RNAs. Nat Struct Mol Biol 22: 5-7, 2015.

7. Sun M, Nie F, Wang Y, Zhang Z, Hou J, He D, Xie M, Xu L, De W, Wang Z Wang J: LncRNA HOXA11-AS promotes proliferation and invasion of gastric cancer by scaffolding the chromatin modification factors PRC2, LSD1, and DNMT1. Cancer Res 76 6299-6310, 2016.

8. Peter S, Borkowska E, Drayton RM, Rakhit CP, Noon A, Chen W and Catto JW: Identification of differentially expressed long noncoding RNAs in bladder cancer. Clin Cancer Res 20: 5311-5321, 2014
9. Wang K, Liu CY, Zhou LY, Wang JX, Wang M, Zhao B, Zhao WK, Xu SJ, Fan LH, Zhang XJ, et al: APF lncRNA regulates autophagy and myocardial infarction by targeting miR-188-3p. Nat Commun 6: 6779, 2015.

10. Yang G, Lu X and Yuan L: LncRNA: A link between RNA and cancer. Biochim Biophys Acta 1839: 1097-1109, 2014.

11. Schmitt AM and Chang HY: Long noncoding RNAs in cancer pathways. Cancer Cell 29: 452-463, 2016.

12. Liang H, Yu T, Han Y, Jiang H, Wang C, You T, Zhao X, Shan H, Yang R, Yang L, et al: LncRNA PTAR promotes EMT and invasion-metastasis in serous ovarian cancer by competitively binding miR-101-3p to regulate ZEB1 expression. Mol Cancer 17: 119,2018

13. Zheng HT, Shi DB, Wang YW, Li XX, Xu Y, Tripathi P, Gu WL, Cai GX and Cai SJ: High expression of lncRNA MALAT1 suggests a biomarker of poor prognosis in colorectal cancer. Int J Clin Exp Pathol 7: 3174-3181, 2014.

14. Qiu JJ, Lin YY, Ye LC, Ding JX, Feng WW, Jin HY, Zhang Y, Li Q and Hua KQ: Overexpression of long non-coding RNA HOTAIR predicts poor patient prognosis and promotes tumor metastasis in epithelial ovarian cancer. Gynecol Oncol 134: 121-128, 2014.

15. Chen ZJ, Zhang Z, Xie BB and Zhang HY: Clinical significance of up-regulated lncRNA NEAT1 in prognosis of ovarian cancer. Eur Rev Med Pharmacol Sci 20: 3373-3377, 2016.

16. An J, Lv W and Zhang Y: LncRNA NEAT1 contributes to paclitaxel resistance of ovarian cancer cells by regulating ZEB1 expression via miR-194. Onco Targets Ther 10: 5377-5390, 2017.

17. Chai Y, Liu J, Zhang Z and Liu L: HuR-regulated lnc RNA NEAT 1 stability in tumorigenesis and progression of ovarian cancer. Cancer Med 5: 1588-1598, 2016.

18. Ambros V: The functions of animal microRNAs. Nature 431: 350-355, 2004

19. Garzon R, Calin GA and Croce CM: MicroRNAs in cancer. Annu Rev Med 60: 167-179, 2009.

20. Zuberi M, Khan I, Mir R, Gandhi G, Ray PC and Saxena A: Utility of serum miR-125b as a diagnostic and prognostic indicator and its alliance with a panel of tumor suppressor genes in epithelial ovarian cancer. PLoS One 11: e0153902, 2016.

21. Cai M, Chen Q, Shen J, Lv C and Cai L: Epigenetic silenced miR-125a-5p could be self-activated through targeting Suv39H1 in gastric cancer. J Cell Mol Med 22: 4721-4731, 2018.

22. Wu J, Miao J, Ding Y, Zhang Y, Huang X, Zhou X and Tang R: MiR-4458 inhibits breast cancer cell growth, migration, and invasiveness by targeting CPSF4. Biochem Cell Biol 97: 722-730, 2019.

23. Jima DD, Zhang J, Jacobs C, Richards KL, Dunphy $\mathrm{CH}$, Choi WW, Au WY, Srivastava G, Czader MB, Rizzieri DA, et al: Deep sequencing of the small RNA transcriptome of normal and malignant human B cells identifies hundreds of novel microRNAs. Blood 116: e118-e127, 2010.

24. Griffiths-Jones S, Grocock RJ, Van Dongen S, Bateman A and Enright AJ: miRBase: microRNA sequences, targets and gene nomenclature. Nucleic Acids Res 34: D140-D144, 2006.

25. Zhang L, Qian J, Qiang Y, Huang H, Wang C, Li D and Xu B: Down-regulation of miR-4500 promoted non-small cell lung cancer growth. Cell Physiol Biochem 34: 1166-1174, 2014.

26. Yu FY, Tu Y, Deng Y, Guo C, Ning J, Zhu Y, Lv X and Ye H: MiR-4500 is epigenetically downregulated in colorectal cancer and functions as a novel tumor suppressor by regulating HMGA2. Cancer Biol Ther 17: 1149-1157, 2016.

27. Mitra P, Vaughan PS, Stein JL, Stein GS and van Wijnen AJ: Purification and functional analysis of a novel leucine-zipper/ nucleotide-fold protein, BZAP45, stimulating cell cycle regulated histone H4 gene transcription. Biochemistry 40: 10693-10699, 2001.

28. Li S, Chai Z, Li Y, Liu D, Bai Z, Li Y and Situ Z: BZW1, a novel proliferation regulator that promotes growth of salivary muocepodermoid carcinoma. Cancer Lett 284: 86-94, 2009.

29. Kurman RJ, Carcangiu ML, Herrington CS and Young RH: WHO classification of tumours of female reproductive organs, fourth edition. Lyon, IACR 2014

30. Livak KJ and Schmittgen TD: Analysis of relative gene expression data using real-time quantitative PCR and the 2(-Delta Delta C(T)) method. Methods 25: 402-408, 2001.

31. Sun M, Liu X, Lu K, Nie F, Xia R, Kong R, Yang J, Xu T, Liu Y, Zou Y, et al: EZH2-mediated epigenetic suppression of long noncoding RNA SPRY4-IT1 promotes NSCLC cell proliferation and metastasis by affecting the epithelial-mesenchymal transition. Cell Death Dis 5: e1298, 2014. 
32. Mercer TR, Dinger ME and Mattick JS: Long non-coding RNAs: Insights into functions. Nat Rev Genet 10: 155-159, 2009.

33. Mourtada-Maarabouni M, Pickard M, Hedge V, Farzaneh F and Williams G: GAS5, a non-protein-coding RNA, controls apoptosis and is downregulated in breast cancer. Oncogene 28 195-208, 2009.

34. Sun M, Jin FY, Xia R, Kong R, Li JH, Xu TP, Liu YW, Zhang EB Liu XH and De W: Decreased expression of long noncoding RNA GAS5 indicates a poor prognosis and promotes cell proliferation in gastric cancer. BMC Cancer 14: 319, 2014.

35. Pickard MR and Williams GT: Regulation of apoptosis by long non-coding RNA GAS5 in breast cancer cells: Implications for chemotherapy. Breast Cancer Res Treat 145: 359-370, 2014

36. Hirose T, Virnicchi G, Tanigawa A, Naganuma T, Li R, Kimura H, Yokoi T, Nakagawa S, Bénard M, Fox AH and Pierron G: NEAT1 long noncoding RNA regulates transcription via protein sequestration within subnuclear bodies. Mol Biol Cell 25: 169-183, 2014.

37. Choudhry H, Albukhari A, Morotti M, Haider S, Moralli D, Smythies J, Schödel J, Green CM, Camps C, Buffa F, et al: Tumor hypoxia induces nuclear paraspeckle formation through HIF-20 dependent transcriptional activation of NEAT1 leading to cancer cell survival. Oncogene 34: 4482-4490, 2015.

38. Chakravarty D, Sboner A, Nair SS, Giannopoulou E, Li R, Hennig S, Mosquera JM, Pauwels J, Park K, Kossai M, et al: The oestrogen receptor alpha-regulated lncRNA NEAT1 is a critical modulator of prostate cancer. Nat Commun 5: 5383, 2014.
39. Ding $\mathrm{N}, \mathrm{Wu} \mathrm{H}$, Tao $\mathrm{T}$ and Peng E: NEAT1 regulates cell proliferation and apoptosis of ovarian cancer by miR-34a-5p/BCL2. Onco Targets Ther 10: 4905-4915, 2017.

40. Paraskevopoulou MD and Hatzigeorgiou AG: Analyzing miRNA-lncRNA interactions. Methods Mol Biol 1402: 271-286, 2016.

41. Jalali S, Bhartiya D, Lalwani MK, Sivasubbu S and Scaria V: Systematic transcriptome wide analysis of lncRNA-miRNA interactions. PLoS One 8: e53823, 2013.

42. Li JH, Zhang SQ, Qiu XG, Zhang SJ, Zheng SH and Zhang DH: Long non-coding RNA NEAT1 promotes malignant progression of thyroid carcinoma by regulating miRNA-214. Int J Oncol 50: 708-716, 2017.

43. Liu F, Zhao H, Gong L, Yao L, Li Y and Zhang W: MicroRNA-129-3p functions as a tumor suppressor in serous ovarian cancer by targeting BZW1. Int J Clin Exp Pathol 11: 5901-5908, 2018

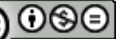

This work is licensed under a Creative Commons Attribution-NonCommercial-NoDerivatives 4.0 International (CC BY-NC-ND 4.0) License. 